\title{
shRNA targeting Bmi1 impedes the self-renewal of cisplatin-enriched stem-like cells in human A549 cells
}

\author{
YU XU, YI-DE HU, JING ZHOU, MING-HUI ZHANG, WEI-WEI YUAN and YAN LUO \\ The Third Department of Oncology, PLA Cancer Research Institute of the Second Affiliated \\ Hospital, The Third Military Medical University, Chongqing 400037, P.R. China
}

Received March 8, 2012; Accepted April 18, 2012

DOI: $10.3892 /$ or.2012.1843

\begin{abstract}
It has been hypothesized that cancer stem-like cells are responsible for tumor recurrence following chemotherapy. Evidence on the mechanisms through which drug-resistant stem-like cells recapitulate the tumor mass has not been definitively reported. Based on this information, we investigated the enrichment ability of a population of stem-like cells following treatment with cisplatin in human A549 cells and focused on the molecular mechanisms regulating the self-renewal of stem-like cells. A population of stem-like cells was enriched following cisplatin treatment and was defined phenotypically and functionally based on the expression of certain stem cell markers, sphere-forming ability, multipotent differentiation and induction of xenograft tumors in vivo. For various types of differentiated cells, Bmil has been reported to be important for cell proliferation and for the self-renewal of stem cells. The high expression of Bmil in cisplatin-enriched stem-like cells was shown using Q-PCR and western blotting; therefore, the role of Bmil was investigated in cisplatin-enriched stem-like cells by infecting cisplatin-enriched stem-like cells with Bmiltargeted RNAi lentiviruses. Cell proliferation, tumor sphere formation and xenograft formation was reduced following knockdown of Bmil. Based on our results, we propose that, after cisplatin treatment, Bmil is required for the self-renewal of stem-like cells that are important for the expansion of the stem-like cell pool in human A549 cells and that targeting Bmil slows down the formation of tumors in vivo.
\end{abstract}

\section{Introduction}

A small population of malignant cells within an organ can rapidly expand and ultimately disrupt organ function (1). These

Correspondence to: Dr Yi-De Hu, The Third Department of Oncology, PLA Cancer Research Institute of the Second Affiliated Hospital, The Third Military Medical University, Chongqing 400037, P.R. China

E-mail: huyide_mit@yahoo.com.cn

Key words: self-renewal, lung cancer, stem-like cells, Bmil, cisplatin cells were previously referred to as cancer-initiating cells or cancer stem-like cells (CSCs) based on their high capacity for self-renewal, multilineage differentiation, and elevated capacity to induce malignancy $(2,3)$. CSCs, first identified in acute leukemia, have now been isolated from several human malignancies, including breast, brain, prostate, ovarian and lung cancers (4-6).

Lung cancer is the most common malignancy worldwide. While advancements in early diagnosis and treatment have been made in the hope of improving survival, recurrence remains a major obstacle to achieving a cure. After complete surgical resection, reported recurrence rates range from 30 to $75 \%$ (7). Accumulating evidence suggests that CSCs are responsible for tumor regeneration following chemotherapy due to their high drug resistance and tumorigenicity (8-10). The initial isolation of lung cancer stem-like cells (LCSCs) relied on a basic knowledge of normal stem cells in the bronchioalveolar duct junction, assays for their functionality, and expression levels of the specific markers Sca ${ }^{+}$and CD34 ${ }^{+}$ on the cell membranes. Taken together, this knowledge provided robust means for the identification of the elusive CSCs within an induced mouse lung cancer model (11). In an additional study, cells co-expressing $\mathrm{CD} 133^{+} / \mathrm{CD} 326^{+}$were isolated from lung cancer patients and were characterized as human lung cancer stem-like cells (12). In the absence of such specific targets for identification purposes, lung cancer stem-like cells were also identified using flow cytometrybased side population cell sorting from lung cancer cell lines $(13,14)$. These methods, however, do not provide a direct model to assess the mechanism by which cancer stem cells recover from chemotherapy treatment $(15,16)$. Here, we report another approach to enriching drug-resistant stem-like cells from the human lung cancer cell line A549. This model was used to study the role of stem-like cells in the recurrence of lung cancer in vitro.

The potential for CSCs to proliferate and self-renew is remarkable. As few as $10 \mathrm{CSCs}$ can initiate tumor formation in a mouse model (17). There is evidence to suggest that certain signaling pathways regulating self-renewal and proliferation are abnormal in CSCs $(18,19)$. Polycomb group protein B lymphoma Mo-MLV insertion region 1 homolog (Bmi1) was originally identified as an oncogene that cooperates with c-Myc in a murine lymphomagenesis model. There is also evidence indicating that Bmil plays an essential role in maintaining the 
self-renewal of mouse bronchioalveolar stem cells in a mouse model (20). However, the role of Bmil in the recurrence of the tumor mass derived from stem-like cells following chemotherapy was not studied.

In this study, we used cisplatin treatment to enrich a population of stem-like cells in the human cell line A549 and elucidated the mechanisms underlying the self-renewal and expansion of cisplatin-enriched stem-like cells (CESCs). We demonstrated that Bmil is consistently overexpressed in CESCs. Additionally, we showed that the downregulation of Bmil suppressed the self-renewal of CESCs and the growth of xenografts. Our study demonstrates that Bmil is involved in controlling the self-renewal of stem-like cells after cisplatin treatment in human A549 cells, providing insight into the mechanism underlying the recurrence of lung cancer following chemotherapy.

\section{Materials and methods}

Cell culture. The human lung cancer cell line A549 was obtained from the American Type Culture Collection (ATCC, Rockville, MD) and was cultured in RPMI-1640 (HyClone, Logan, UT) with $10 \%$ fetal bovine serum (FBS) (Gibco, Grand Island, $\mathrm{MI})$ at $37^{\circ} \mathrm{C}$ and $5 \% \mathrm{CO}_{2}$.

Cisplatin-enriched stem-like cells. Following cisplatin treatment $(5 \mu \mathrm{g} / \mathrm{ml})$ for 3 days, A549 cells were cultured for 4 weeks until drug-surviving colonies were established (21). The remaining drug-surviving cells (DSCs) were then cultured in DMEM/F12 serum-free medium containing $50 \mu \mathrm{g} / \mathrm{ml}$ insulin, $100 \mu \mathrm{g} / \mathrm{ml}$ apo-transferrin, $10 \mu \mathrm{g} / \mathrm{ml}$ putrescine, $0.03 \mathrm{mM}$ sodium selenite, $2 \mu \mathrm{M}$ progesterone, $0.6 \%$ glucose, $5 \mathrm{mM}$ HEPES, $0.1 \%$ sodium bicarbonate, $0.4 \%$ BSA, glutamine and antibiotics (Hyclone), as well as $20 \mathrm{ng} / \mathrm{ml} \mathrm{EGF,} 10 \mathrm{ng} / \mathrm{ml} \mathrm{bFGF}$ and $10 \mathrm{ng} / \mathrm{ml} \mathrm{LIF} \mathrm{(8).} \mathrm{The}$ third-generation of spheres that developed from DSCs was termed CESCs.

Cell surface marker analysis by flow cytometry. Cells $\left(2 \times 10^{5}\right)$ were placed in $100 \mu \mathrm{l}$ PBS and incubated with $10 \mu \mathrm{l}$ anti-human CD133-PE conjugated antibody (Miltenyi, Auburn, CA). Cells were then washed, resuspended in PBS with $2 \mu \mathrm{l}$ of 7-AAD solution (Pharmingen, San Diego, CA), and analyzed using an Epic XL flow cytometer (Beckman Coulter, Brea, CA).

Immunofluorescent staining. Tumor spheres were collected and placed on Matrigel-coated coverslips. After being cultured for $2 \mathrm{~h}$, the spheres were fixed in $4 \%$ paraformaldehyde for 20 min at RT. A549 cells, DSCs, and CESCs were then labeled with anti-human CD133 (1:300, rabbit polyclonal, Abcam, Cambridge, UK) and anti-human Bmil (1:50, rabbit polyclonal, Santa Cruz Biotechnology, Santa Cruz, CA) antibodies at $4^{\circ} \mathrm{C}$ overnight. Secondary antibodies, including FITC-conjugated goat anti-rabbit IgG or Cy3-conjugated goat anti-rabbit IgG (1:200 dilution, Jackson ImmunoResearch, West Grove, PA), were incubated with samples for $1 \mathrm{~h}$ at $37^{\circ} \mathrm{C}$.

To assess the multipotency of the collected tumor spheres, anti-human CK8 and anti-human CK18 antibodies were used to stain differentiated spheres. All cells were also counterstained with 4,6-diamidino-2-phenylindole (DAPI; $100 \mathrm{mg} / \mathrm{ml}$, Sigma) to detect cell nuclei. Images were collected and analyzed using a Leica laser scanning confocal microscope and LAS AF software (Leica, Mannheim, Germany).

Sphere-forming assay. A549 cells, DSCs and tumor spheres were dissociated with TrypLE ${ }^{\mathrm{TM}}$ Express (Invitrogen, Carlsbad, CA) into single-cell suspensions. The cells were then inoculated into DMEM/F12 serum-free medium containing $50 \mathrm{ng} / \mathrm{ml}$ insulin, $100 \mathrm{ng} / \mathrm{ml}$ apo-transferrin, $10 \mathrm{ng} / \mathrm{ml}$ putrescine, $0.03 \mathrm{mM}$ sodium selenite, $2 \mathrm{nM}$ progesterone, $0.6 \%$ glucose, $5 \mathrm{mM}$ HEPES, $0.1 \%$ sodium bicarbonate, $0.4 \%$ BSA, glutamine and antibiotics (Hyclone), as well as $20 \mathrm{ng} / \mathrm{ml} \mathrm{EGF,} 10 \mathrm{ng} / \mathrm{ml} \mathrm{bFGF}$, and $10 \mathrm{ng} / \mathrm{ml} \mathrm{LIF}$ using serial diluting methods into 96-well plates (Corning Inc., Corning, NY). Only wells containing a single cell were counted. Wells containing more than one cell or no cells were marked and dismissed from statistical data. After 6-10 days of culture, wells that contained spheres were counted using inverted phase contrast microscopy (Leica). The percentage cells with sphere-forming capacity was calculated as the numbers of wells with sphere/numbers of total wells with single cell x $100 \%$.

Differentiation. Cells dissociated from T3 spheres were plated at a density of $1 \times 10^{4}$ cells $/ \mathrm{ml}$ on 24-well plates pre-coated with collagen IV (BD Biosciences, San Jose, CA) in culture media supplemented with $10 \%$ FBS without growth factors. Upon confluence, cells were stained with anti-human CK8 and antihuman CK18 antibodies as described above.

In vivo analysis of tumor growth. All procedures involving animals were approved by the Third Military Medical University Animal Care and Use Committee (Chongqing, China; No.2008-03). A549 cells and T3 spheres (100, 1,000, 10,000 or 100,000 cells) were injected subcutaneously into the left flank of 5-week-old NOD/SCID mice (6 mice/group). Tumor size was measured using calipers, and tumor volume was calculated using the equation $\mathrm{V}=\pi / 6$ (length $\mathrm{x}$ width $\mathrm{x}$ height).

Generation of Bmil RNAi lentiviruses. After testing knockdown efficiencies of several shRNA constructs, the following shRNA oligonucleotides were utilized: 5'-AAGGAGGAGGT GAATGATAAA-3' (to target the open reading frame of Bmil), 5'-AGAATTGGTTTCTTGGAAA-3' and 5'-CGGAAAGA ATATGCATAGA-3' (to target two sites in the $3^{\prime}$ untranslated region of Bmi1), the loop sequence (TTCAAGAGA), and the reverse complement of each targeting sequence. A non-specific shRNA was also synthesized as a control, and each shRNA was cloned into a pGCL-GFP plasmid containing the U6 promoter and green fluorescent protein (GFP) (Genechem, Shanghai, China). The plasmids pHelper 1.0 and pHelper 2.0 were also included to provide the necessary packaging elements needed for lentivirus production. For viral transduction, shRNA lentiviral vectors at a multiplicity of infection (MOI) of 50 were added to dispersed CESCs just after plating. Bmil protein levels and GFP fluorescence were measured $72 \mathrm{~h}$ post-transduction. 
Quantitative real-time RT-PCR. cDNA $(2 \mu \mathrm{l})$ was subjected to real-time quantitative RT-PCR using SYBR-Green as a fluorescent reporter and Real Master Mix (Tiangen, Beijing, China). Specific gene primers for $A B C G 2, B m i 1$, and the internal control gene, $\beta$-actin, were amplified in separate reaction tubes. Threshold cycle numbers (CTs) of triplicate reactions were determined using ABI-7500 software and averaged. Levels of specific gene expression were normalized to $\beta$-actin levels using the formula $2^{-\Delta \mathrm{CT}}$, where $\Delta \mathrm{CT}$ is the $\mathrm{CT}$ of the housekeeping gene ( $\beta$-actin) subtracted from the CT of the target gene. The absence of primer dimers was confirmed, and the specificity of the products was obtained using melt curve analysis. The primers sequences used included: ABCG2, 5'-C AGGTGGAGGCAAATCTTCGT-3' (forward) and 5'-ACAC ACCACGGATAAACTGA-3' (reverse) (22); Bmi1, 5'-CTGG TTGCCCATTGACAGC-3' (forward) and 5'-CAGAAAATG AATGCGAGCCA-3' (reverse) (23); $\beta$-actin, 5'-CCTGGCAC CCAGCACAAT-3' (forward) and 5'-GCCGATCCACACG GAGTACT-3' (reverse).

Western blot analysis. Cell extracts of CESCs, CESCs ${ }^{\mathrm{NC}}$ and $\mathrm{CESCs}{ }^{\text {Bmil- }}$ were collected, and protein concentrations were determined using a BCA Protein Assay Kit (HyclonePierce). Protein samples $(50 \mu \mathrm{g})$ were then electrophoresed on $12 \%$ SDS-polyacrylamide gels and transferred onto polyvinylidene fluoride (PVDF) membranes. Membranes were blocked in 5\% non-fat dry milk in Tris-buffered saline (TBS) for $1 \mathrm{~h}$ at RT and incubated with anti-Bmi1, anti-p14ARF, anti-MDM2, and anti-p53 antibodies (diluted 1:200, Santa Cruz Biotechnology) overnight at $4^{\circ} \mathrm{C}$. After 3 washes with TBS-Tween-20 (TBST), membranes were incubated with anti-mouse IgG or anti-rabbit IgG horseradish peroxidase conjugated antibodies (diluted 1:2000, Zhongshan Goldenbridge Biotechnology, Beijing, China) for $2 \mathrm{~h}$ at RT. Each membrane was also incubated with an anti$\alpha$-tubulin antibody (Santa Cruz Biotechnology) as a loading control. Membranes were washed three times with TBST, and bound antibodies were detected using ECL (Beyotime, Jiangsu, China). Protein levels were quantitated by densitometry using Quantity One software (Bio-Rad Laboratories, Munich, Germany).

WST-1 assay. CESC, CESC ${ }^{\mathrm{NC}-}$ and $\mathrm{CESC}^{\text {Bmil- }}$ spheres $\left(1 \times 10^{3}\right.$ cells each) were plated on 24-well plates and cultured for 6 days. WST-1 ((4-[3-(4-Iodophenyl)-2H-5-tetrazolio)]-1,3benzene-disulfonate) is cleaved to formazan, which is soluble in culture medium and can be correlated with the number of metabolically active cells present in the culture. The proliferation index for these assays was determined each day for 6 days after seeding using the Cell Proliferation Reagent WST-1 (Beyotime, Jiangsu, China).

Statistical analyses. All experiments were performed at least three times and representative results are presented as the mean values \pm standard deviation (SD). The data were analyzed using SPSS v13.0 software (SPSS Inc., Chicago, IL, USA). Statistical analysis was performed by one-way analysis of variance (ANOVA), and comparisons among groups were achieved using independent sample t-tests. Statistical significance was established at values of $\mathrm{P}<0.05$.

\section{Results}

In vitro cisplatin treatment combined with serum-free culture selective enrichment for self-renewing tumor spheres. Tumors that recur after an initial response to chemotherapy are resistant to multiple drugs (24). Cancer cells are thought to acquire resistance to chemotherapy through two mechanistic categories, innate drug resistance and acquired drug resistance (25). Similar to normal stem cells, cancer stem-like cells are capable of innate drug resistance due to their ability to pump out toxic drugs (26). We treated the lung cancer cell line A549 with the conventional chemotherapy drug cisplatin for 3 days. As described by Levina et al (21), a vast majority of the cells died. A portion of the surviving cells resembled senescent cells with enlarged and flattened morphology. These cells grew larger in size and disaggregated during the 10-20 days following drug treatment. Small, round, or spindle-shaped cells with lower adherence appeared during the first week after drug treatment, and their growing colonies gradually replaced the 'senescent' cells (Fig. 1A-C). These cells were termed drug surviving cells (DSCs).

DSCs were then transferred into a low-adherence plate and cultured at clonal density. A complete serum-free medium was used to selectively 'starve' the cells, which depend on serum and plate attachment to expand, with acquired drug resistance. As expected, a portion of the cells did not form tumor spheres and gradually died, while some tumor spheres were observed floating in the medium (Fig. 1D). A second generation of tumor spheres (T2) was produced by dissociating the first generation (T1) into single cells and culturing accordingly (Fig. 1E). We observed fewer dead cells and more spheres, indicating that the population of acquired drug-resistant cells gradually diminished. In the medium of the third generation of tumor spheres (T3), very few dead cells were detected (Fig. 1F). Based on our observations, we propose that the self-renewing tumor spheres were selectively enriched in the $\mathrm{T} 3$ tumor spheres.

Identifying stem-like cell properties of T3 tumor spheres. To verify that $\mathrm{T} 3$ tumor spheres possess the characteristics of cancer-initiating cells, the T3 tumor spheres were analyzed for expression of the stem cell markers CD133 and ABCG2, sphere-forming capacity, differentiation ability, and tumorigenic potential.

CD133 is a widely accepted marker for stem cells, and expression of CD133 was detected on parental A549, DSCs and isolated T3 spheres by flow cytometry. Based on the flow cytometry assays, $\sim 0.5-1.3 \%$ of A549 cells were $\mathrm{CD} 133^{+}, \sim 20 \%$ of DSCs were $\mathrm{CD}_{133^{+}}$, and $>85 \%$ of $\mathrm{T} 3$ spheres were $\mathrm{CD} 133^{+}$ (Fig. 2A). Additionally, extensive expression of CD133 was detected in T3 sphere samples, while lower levels of CD133 expression were detected for the parental A549 and DSCs based on immunostaining assays (Fig. 2B). Another stem cell marker, which is also responsible for the efflux of Hoechst 33342 by the 'side population', was detected. There was little ABCG2 expression in parental A549, while higher levels of ABCG2 were present in DSCs and T3 spheres (Fig. 2C).

The sphere-forming cells among the parental A549 cells, DSCs, and T3 spheres were examined for their ability to form new spheres after being initially cultured as a single cell. After 2 weeks, $85.34 \%$ of wells with a single cell derived from 


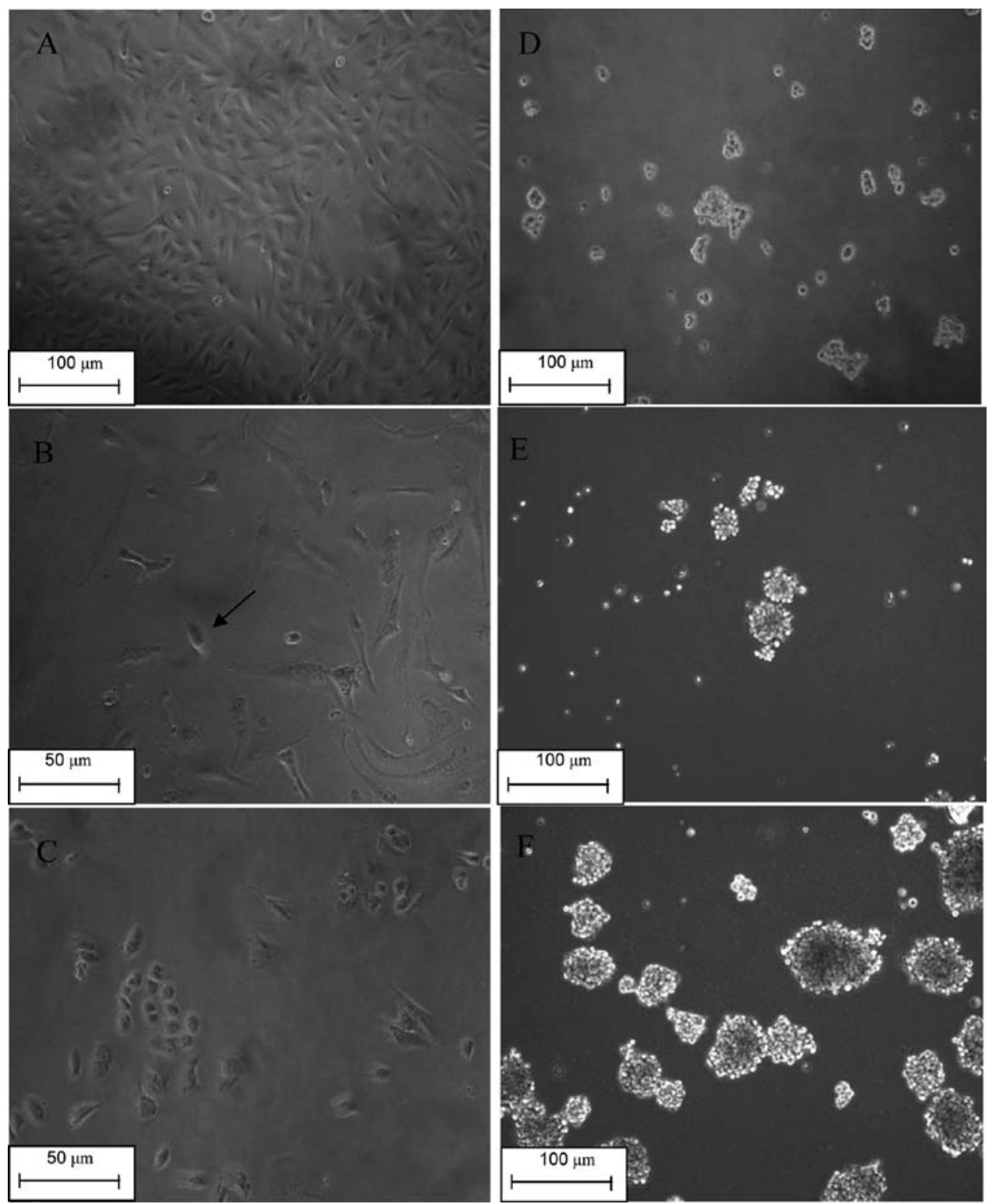

Figure 1. Selection of self-renewal tumor spheres from A549 human lung cancer cells. (A) Morphology of parental A549 cells at x100 magnification. (B) Morphology of DSCs at x200 magnification. Small, round and spindle-shaped cells (indicated with a black arrow) were observed to replace the present 'senescent' cells and to form colonies referred to as DSCs. (C) Morphology of DSCs colonies at x200 magnification. (D) The morphology of T1 tumor spheres at x100 magnification. DSCs were transferred into a low adherence plate and cultured at clonal density to form tumor spheres (first generation). (E) Morphology of T2 tumor spheres at x100 magnification. First generation spheres were consecutively passaged to form T2 and T3 tumor spheres. (F) Morphology of T3 tumor spheres at $\times 100$ magnification.

T3 spheres formed a new set of spheres, while only $23.81 \%$ of wells with a single cell derived from DSCs and $1.63 \%$ of parental A549 cells were able to form spheres (Fig. 3A).

Type I CK18 cytokeratin and type II CK8 cytokeratin are markers for the identification of lung cancer cells (27). These were both detected in parental A549 cells and T3 spheres. Expression of both markers was observed in parental A549 cells, while the same was not observed in T3 spheres (Fig. 3B). When T3 spheres were cultured in media supplemented with $10 \%$ FBS, however, they gradually became adherent and exhibited a morphology similar to that of parental A549 cells, and expression of CK8 and CK18 cytokeratins was restored (Fig. 3C). These results suggest that less differentiated tumor spheres can propagate into differentiated progenies.
To test the hypothesis that $\mathrm{T} 3$ spheres would be more tumorigenic because of their enhanced stem-like properties, T3 spheres and parental A549 cells were injected subcutaneously into NOD/SCID mice in a limiting dilution experiment (i.e., 100, 1,000, 10,000 and 100,000 cells). It was observed that as few as 100 sphere-forming tumor cells could produce a tumor, while absence of tumor formation was observed up to 90 days following the inoculation of 100 or 1,000 parental A549 cells (Table I).

Based on the results described above, the enriched T3 spheres were defined as cisplatin-enriched stem-like cells (CESCs).

CESCs have enhanced Bmil expression and are not quiescent. Prior studies demonstrated that cancer stem cells acquire the 
A
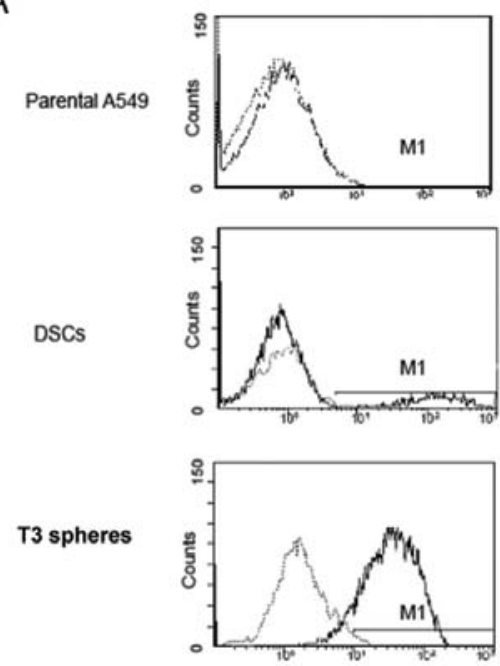

B

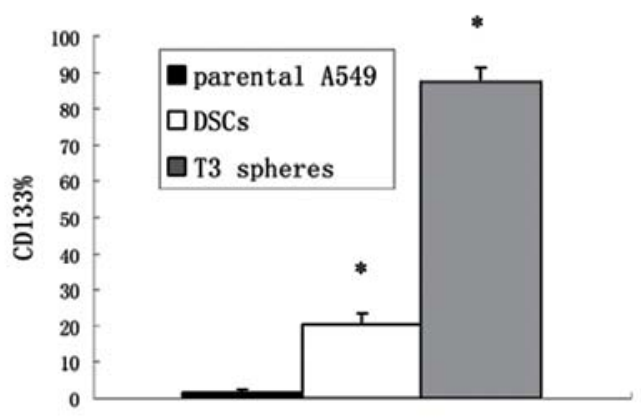

\section{C}
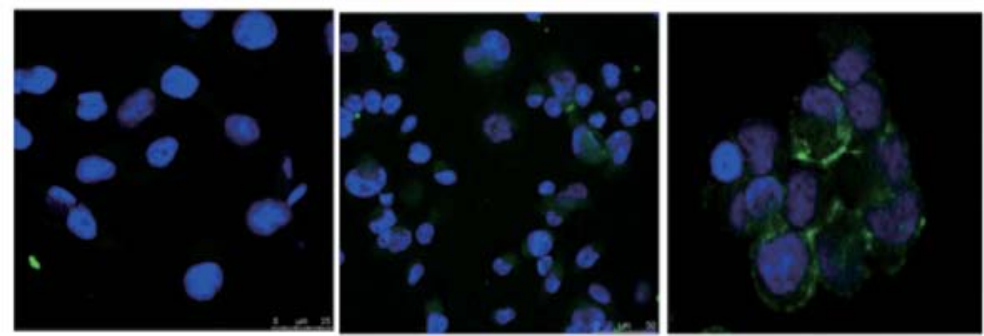

CD133

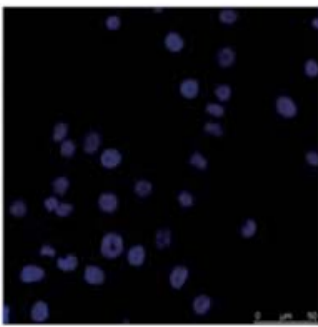

Parental A549

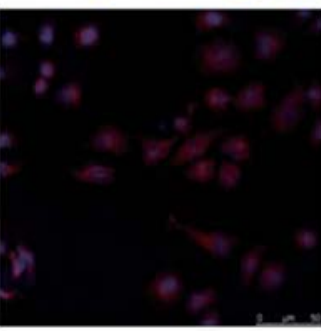

DSCs

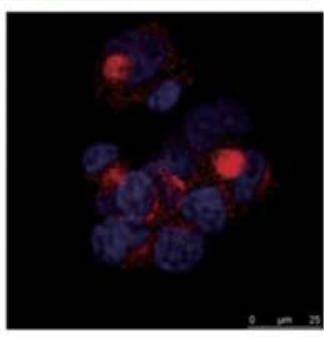

T3 spheres

Figure 2. Stem cell surface markers of the obtained T3 spheres. (A) Flow cytometry analysis of parental A549 cells, DSCs and T3 spheres stained with PE-conjugated antibodies against CD133 are shown on the left. The darker line of each histogram represents the proportion of CD133 ${ }^{+}$cells detected relative to the population of cells stained with mouse IgG isotype control (dashed line). (B) The CD133 ${ }^{+}$population is quantitated for each type of cell assayed (CD1 $33 \%$ ). Data are presented as the means \pm SD. Data are presented as the means \pm SD. (C) Immunofluoresence staining of stem cell markers CD133 and ABCG2, expressed by parental A549 cells, DSCs, and T3 spheres.

self-renewal ability of normal stem cells, yet refuse to remain quiescent (28). We have previously demonstrated that inoculating 10,000 CESCs subcutaneously in NOD/SCID mice can induce the formation of tumor nodules that are palpable in the 8 days following implantation. This time span is significantly shorter than the 4 weeks at minimum required for 10,000 parental A549 cells to form palpable tumor nodules (data not shown). Although these abilities are supposed to remain quiescent, these data indicate that the proliferation and self-renewal of CESCs are accelerated. Elevated levels of Bmi1, a member of the Polycomb group (PcG) gene family, have been observed in hematopoietic stem cell populations. Bmil is also known to be required for the self-renewal of mouse bronchioalveolar stem cells in a mouse model. To evaluate whether Bmil regulates the self-renewing capacity of CESCs, the expression level of Bmil in CESCs was initially examined. Bmil was expressed in the nuclei of parental A549 cells, DSCs and CESCs (Fig. 4A) but was more widely expressed in DSCs and CESCs. Additionally, real-time PCR assays were performed to detect Bmil mRNA levels. In these assays, Bmil mRNA abundance was 3.73 \pm 0.72 -fold and 11.55 \pm 1 .8-fold higher in DSCs and CESCs, respectively, compared to the parental A549 cells (Fig. 4B). Similar results from western blot assays using the same cell types confirmed the finding (Fig. 4C). Together, these findings suggest that Bmil is overexpressed in CESCs relative to parental A549 cells.

Bmil Knockdown slows down the proliferation of CESCs. To investigate the role of Bmil in CESCs proliferation, lentiviruses containing a Bmil-specific shRNA sequence $\left(\mathrm{CESCs}^{\mathrm{Bmi1}-}\right)$ or a scrambled control shRNA sequence $\left(\mathrm{CESCs}^{\mathrm{NC}-}\right)$ were used to infect CESCs. GFP fluorescence 
A

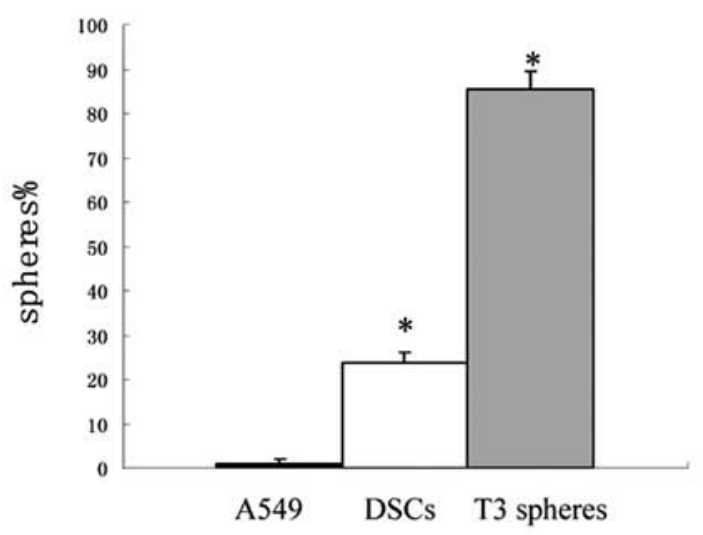

B

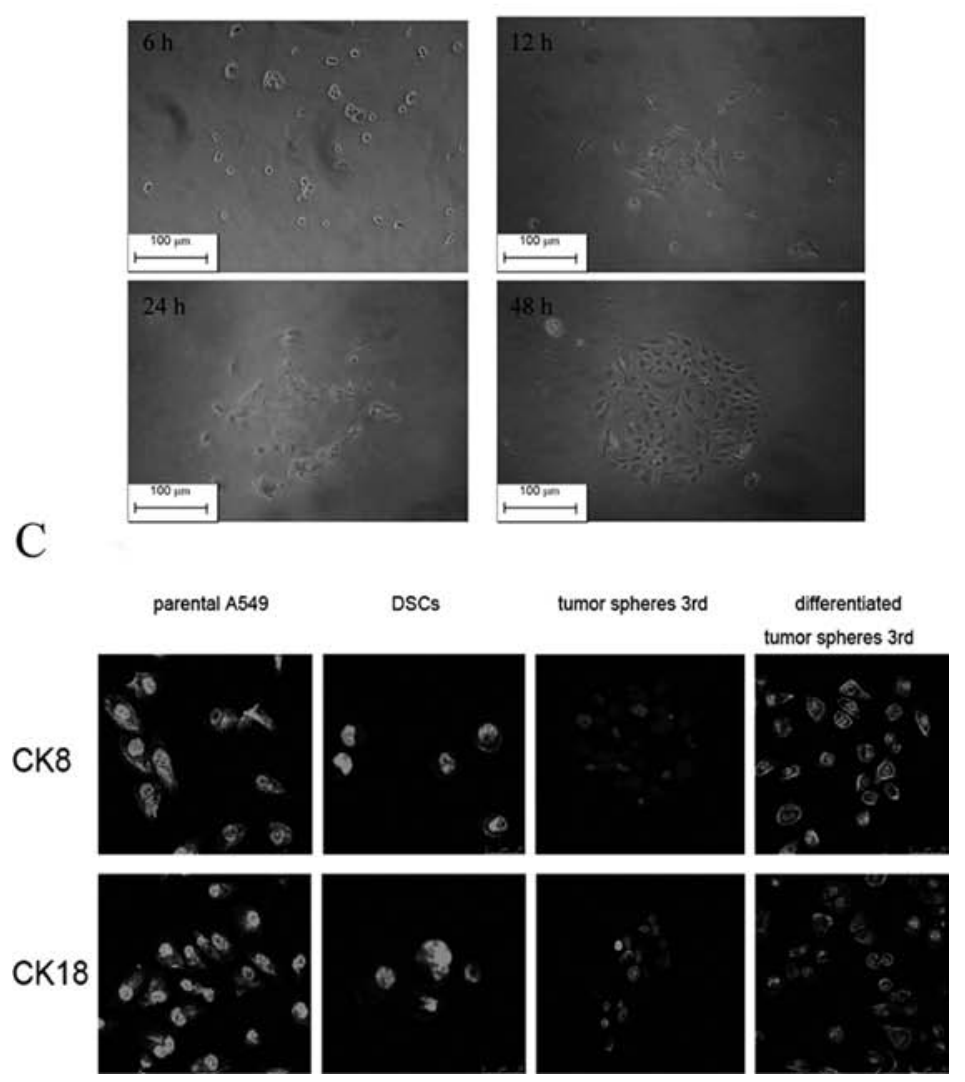

Figure 3. Stem cell properties of the third generation of tumor spheres. (A) The proportion of wells with single cells forming new spheres by parental A549 cells, DSCs, and T3 spheres were quantified (spheres \%). Data presented are the means \pm SD. ${ }^{*} \mathrm{P}<0.001$ compared with parental A549. (B) T3 spheres are dissociated, removed from growth factors, and plated on collagen for 6, 12, 24 and $48 \mathrm{~h}$. (Original magnification, x200). (C) Immunofluoresence staining of differentiated cell markers (CK8 and CK18 as indicated), expressed by parental A549 cells, DSCs, and undifferentiated and differentiated third-generation tumor spheres. After further differentiation $(48 \mathrm{~h})$, they develop into elongated cells with subpopulations staining for either differentiated subtype.

imaging confirmed the high efficiency of infection (Fig. 5A), and western blot assays showed downregulation of Bmi1 expression in CESCs ${ }^{\text {Bmil- }}$ compared to $\mathrm{CESCs}^{\mathrm{NC}-}$ (Fig. 5B). Using WST-1 assays, proliferation of CESCs ${ }^{\text {Bmil- }}$ was also observed to be significantly slower than that of either CESCs or CESCs ${ }^{\mathrm{NC}-}$ beginning the third day after seeding (Fig. 5C; $\mathrm{P}<0.01)$. To determine whether the slower growth rate exhibited by $\mathrm{CESCs}^{\mathrm{Bmil}-}$ was due to an induction of cell death, a trypan blue exclusion test was performed to assess cell viability. As shown in Fig. 5D, significant differences in cell viability were not observed between CESCs, CESCs ${ }^{\text {Bmil- }}$, and $\mathrm{CESCs}^{\mathrm{NC}-}$; therefore, the slower growth rate associated with the $\mathrm{CESC}^{\text {Bmil- }}$ cells was not due to an increase in cell death. Furthermore, the cell cycle analysis of CESCs ${ }^{\text {Bmil- }}$, CESCs, and $\mathrm{CESCs}^{\mathrm{NC}-}$ assessed using flow cytometry revealed an appreciable arrest in the $\mathrm{G} 1$ phase in $\mathrm{CESCs}^{\mathrm{Bmil}-}$ relative to CESCs and CESCs ${ }^{\mathrm{NC}-}$ (Fig. 5E). These results suggest that cell proliferation of CESCs slowed following Bmil knockdown. 
Table I. Incidence of tumors of parental A549 cells and third generation tumor spheres serially transplanted on NOD/SCID mice.

\begin{tabular}{lcccc}
\hline Cell number & $10^{5}$ & $10^{4}$ & $10^{3}$ & $10^{2}$ \\
\hline Parental A549 cells & 5 & 2 & 0 & 0 \\
& & $10^{4}$ & $10^{3}$ & $10^{2}$ \\
T3 spheres & 6 & 4 & 2 \\
\hline
\end{tabular}

Cells $\left(0^{5}, 10^{4}, 10^{3}\right.$ and $\left.10^{2}\right)$ were subcutaneously inoculated into 6 mice for each group. Tumors were monitored every 3 days for up to 60 days.
Bmil is required for the self-renewal and tumorigenesis of CESCs. To test whether Bmil is important for the self-renewal of CESCs, the rate of sphere formation was assayed for $\mathrm{CESCs}^{\text {Bmil- }}$, CESCs and CESCs ${ }^{\mathrm{NC}-}$. The size and rate of sphere formation were both reduced in $\mathrm{CESCs}^{\text {Bmil- }}$, with the spheres being $1 / 5$ to $1 / 6$ the size of control CESCs (Fig. 6A and B). This was due to a lower number of cells being contained in $\mathrm{CESC}^{\text {Bmil- }}$ spheres, which was determined to have 41 cells/ sphere vs. 357 cells/sphere and 313 cells/sphere for CESC and CESC $^{\text {NC- }}$ spheres, respectively (Fig. 6C). In addition, $\sim 100$ spheres $/ \mathrm{ml}, 560 \mathrm{spheres} / \mathrm{ml}$, and $510 \mathrm{spheres} / \mathrm{ml}$ were detected in $\mathrm{CESCs}^{\mathrm{Bmil}-}$, CESCs and $\mathrm{CESCs}^{\mathrm{NC}-}$, respectively (Fig. 6D). It would be more convincing to carry out a sphere-forming

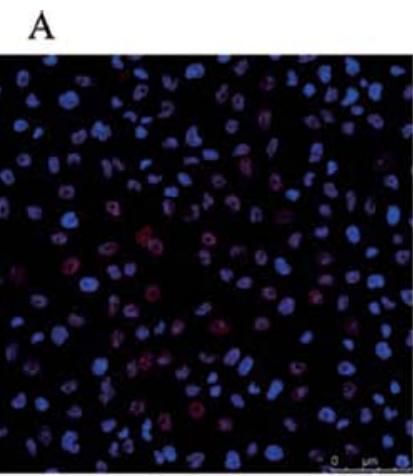

parental A549

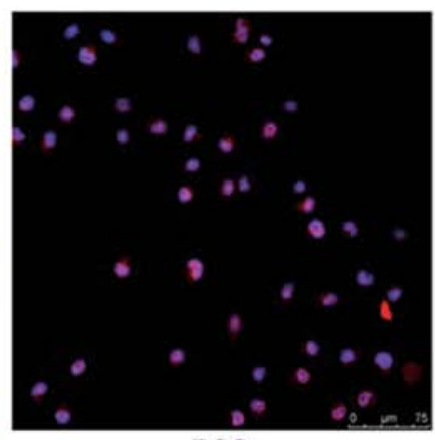

DSCs

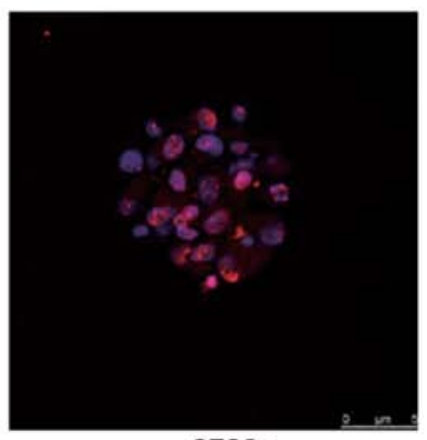

CESCs

B

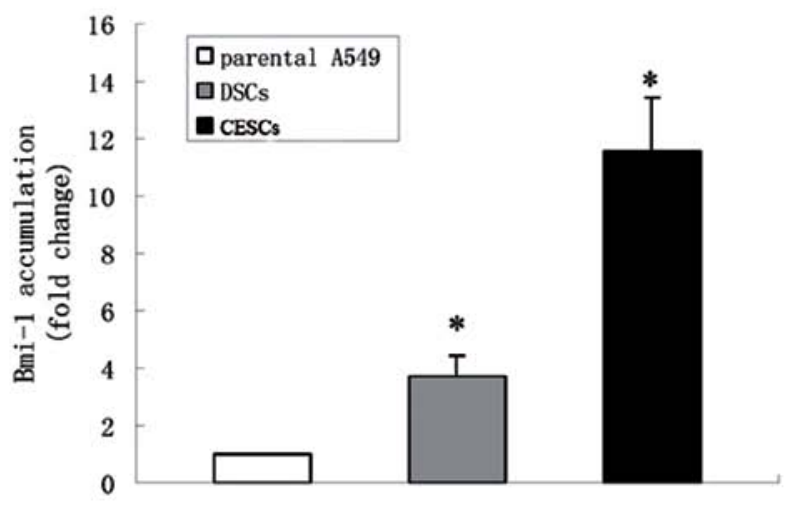

C

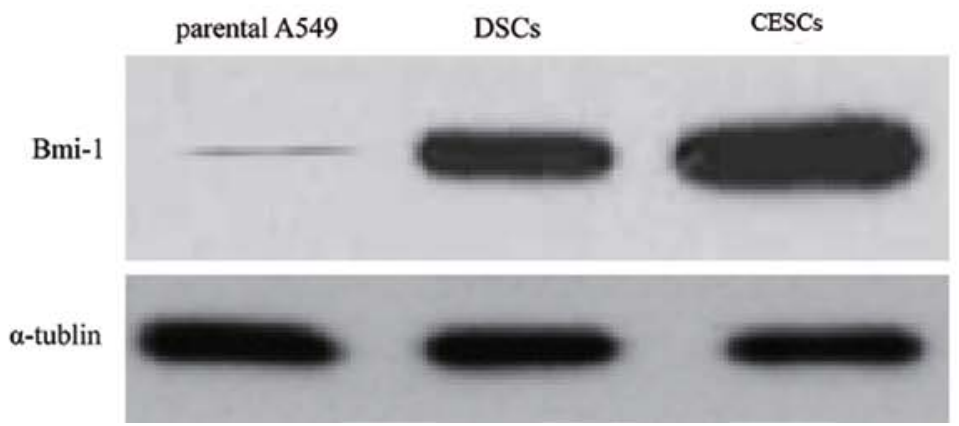

Figure 4. Overexpression of Bmi1 in T3 spheres. (A) Immunofluorescence staining of parental A549 cells, DSCs and T3 spheres with anti-Bmi1 primary antibody. (B) mRNA levels of Bmil detected using real-time RT-PCR and normalized to $\beta$-actin. $2^{-\mathrm{ACT}}$ analysis was performed as described in Materials and methods. Error bars represent the standard error of the mean for assays performed in triplicate. (C) Lysates of parental A549 cells, DSCs and T3 spheres immunoblotted with an anti-Bmil antibody, with detection of $\alpha$-tubulin used as a loading control. 
A

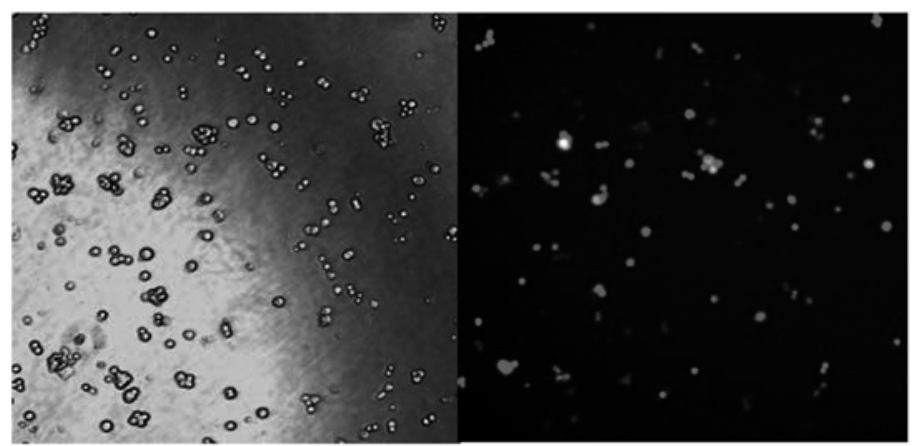

B

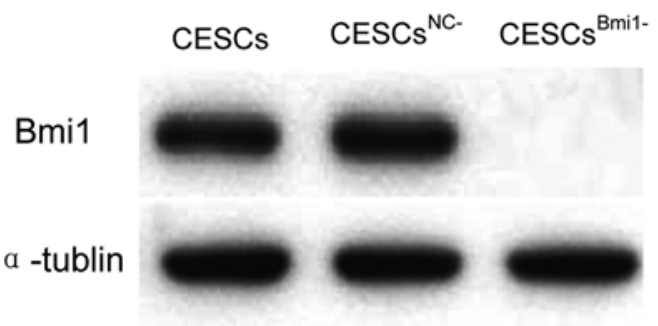

C

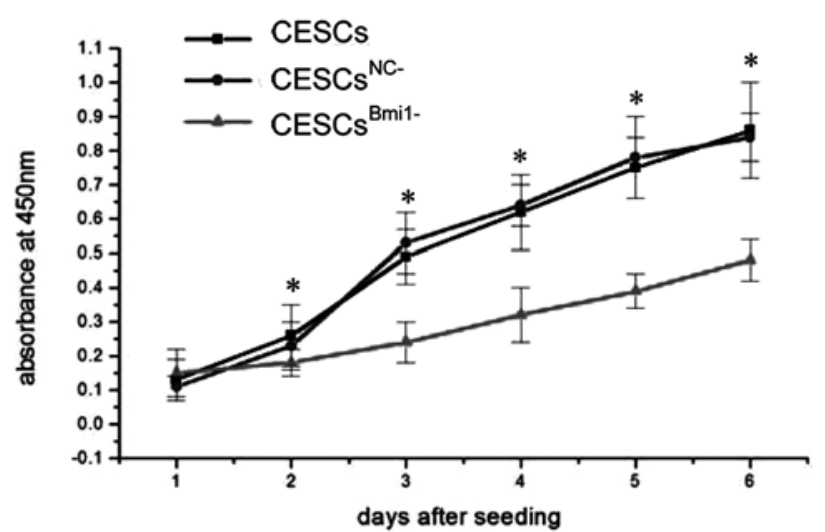

D

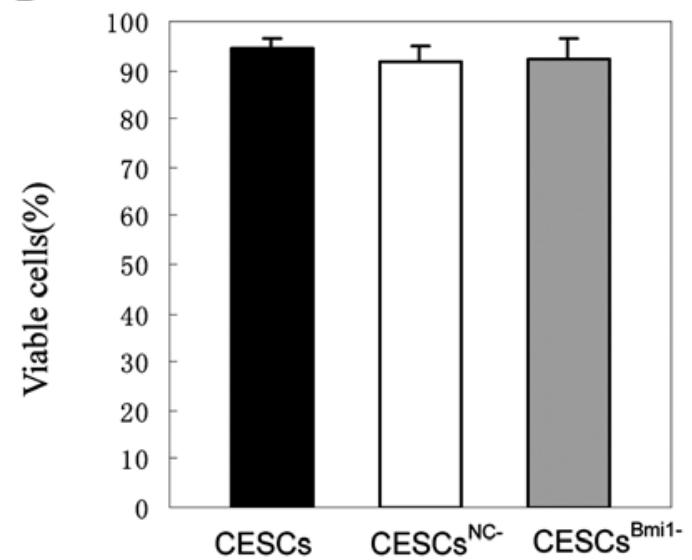

E

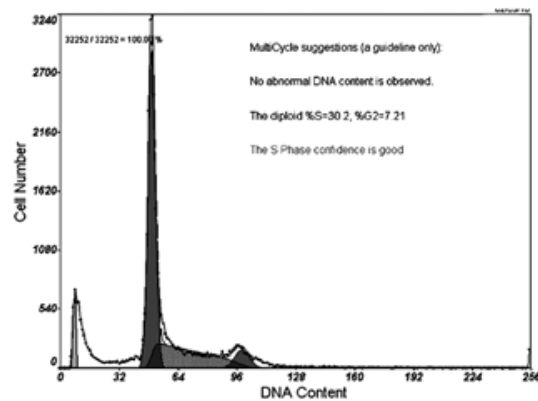

CESCs

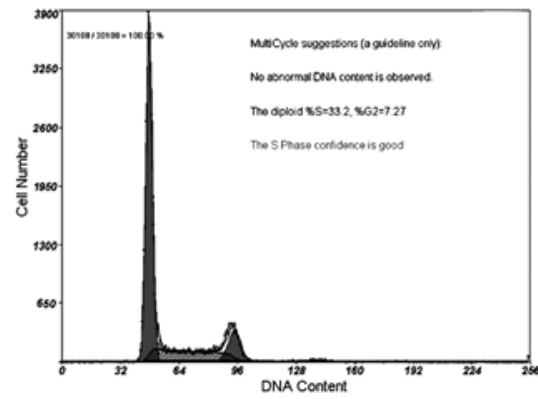

CESCs ${ }^{\mathrm{NC}-}$

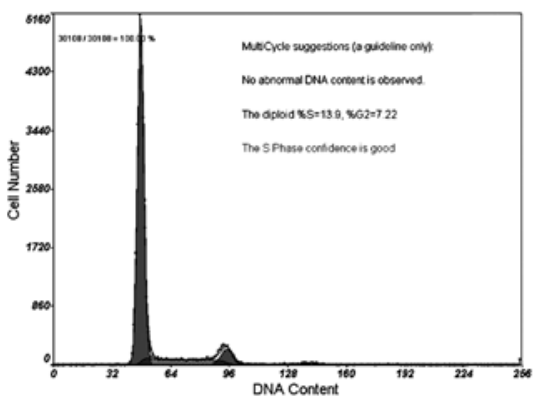

CESCs $^{\text {Bmi1- }}$

Figure 5. The absence of Bmil expression in CESCs affects the formation of tumor spheres and proliferation. (A) A representative white field image of CESC $^{\text {Bmil- }}$ and the corresponding fluorescence image of the GFP expression of the same cell population that represents the efficiency of lentivirus infection achieved (original magnification, x100). (B) Cell lysates of uninfected CESCs (CESCs), CESCs infected with lentiviruses containing Bmil-targeted shRNA $\left(\right.$ CESC $^{\text {Bmil-}}$ ) or non-specific shRNA (CESC ${ }^{\text {NC-}}$ ) were immunoblotted for Bmil, with detection of $\alpha$-tubulin used as a loading control. (C) Growth curves for CESCs, CESCs ${ }^{\mathrm{NC}-}$ and CESCs ${ }^{\mathrm{Bmil}-}$ obtained from WST-1 assay data. Each value represents the mean \pm SD of each triplicate culture. ${ }^{*} \mathrm{P}<0.001$. (D) Cell viability of CESCs, CESCs ${ }^{\mathrm{NC}-}$ and CESCs ${ }^{\mathrm{Bmil}-}$ determined using trypan blue exclusion assays. Each value is the mean \pm SD of triplicate counts. (E) Cell cycle analysis of CESCs, $\mathrm{CESCs}^{\mathrm{NC}-}$ and $\mathrm{CESCs}^{\mathrm{Bmil}-}$ performed by flow cytometry.

assay from single cells and use these cells to determine the role of Bmil. We measured the rate of sphere formation using single CESCs ${ }^{\mathrm{Bmil}-}$, CESCs and $\mathrm{CESCs}^{\mathrm{NC}-}$ for three passages. The rate of sphere formation gradually declined in CESCs ${ }^{\mathrm{Bmil}-}$ but remained stable in CESCs and CESCs ${ }^{\mathrm{NC}-}$ (Fig. 6E). Taken together, these results indicate that the downregulation of Bmil leads to the loss of self-renewal in some CESCs.

Tumor formation assays were also performed by subcutaneously injecting 100,1,000, 10,000 and 100,000 CESCs, $\mathrm{CESCs}^{\mathrm{Bmil-}}$ and CESCs ${ }^{\mathrm{NC}-}$ into NOD/SCID mice. $\mathrm{CESCs}^{\mathrm{Bmil}-}$ cells were associated with a decreased level of tumorigenicity relative to CESCs and CESCs ${ }^{\mathrm{NC}-}$ because at least 10,000 $\mathrm{CESCs}^{\mathrm{Bmil}-}$ were needed to establish a xenograft tumor (Table II). These data indicate that Bmil is required for CESCs to form xenografts.

\section{Discussion}

Lung cancer is the most common malignancy worldwide. Despite a variety of traditional therapeutic methods ranging 
A
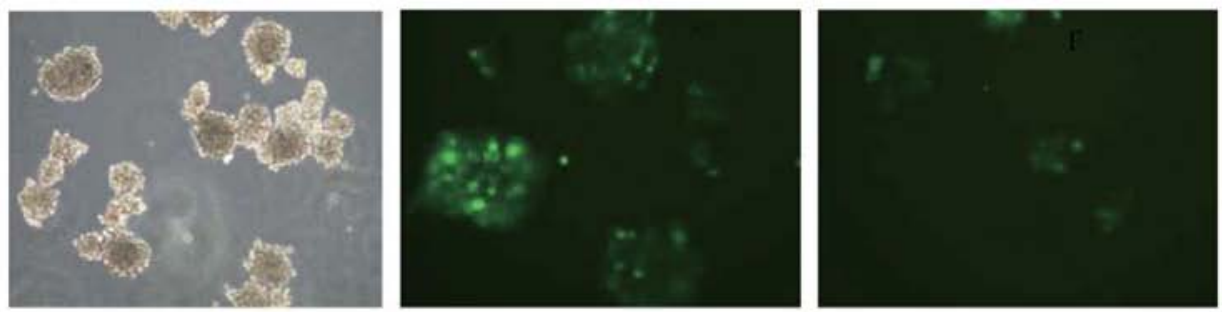

B
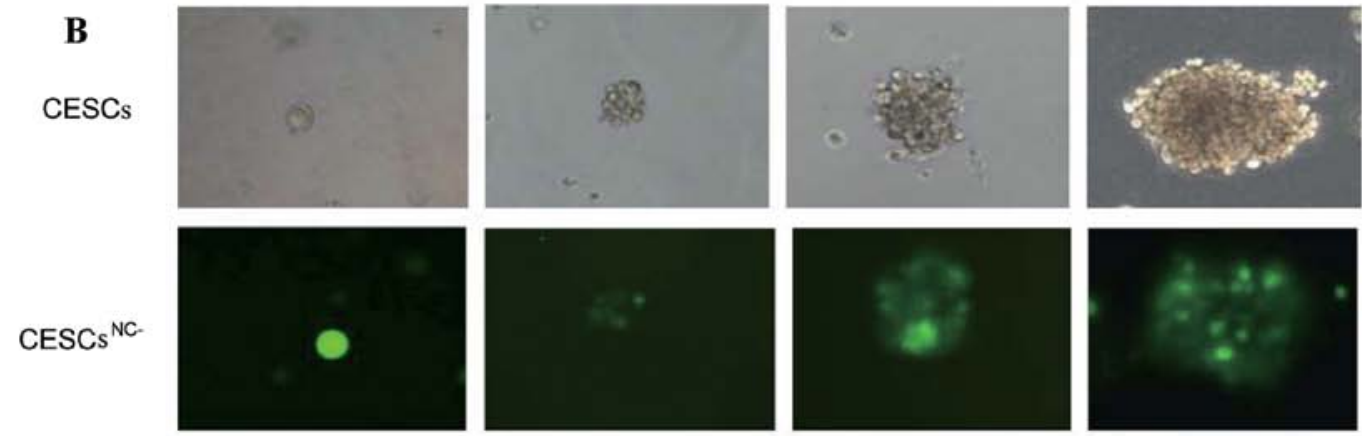

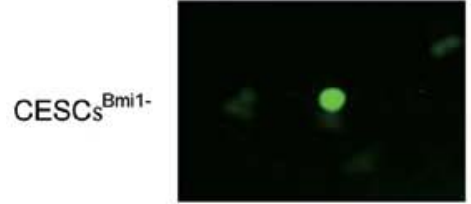

Day 1

C

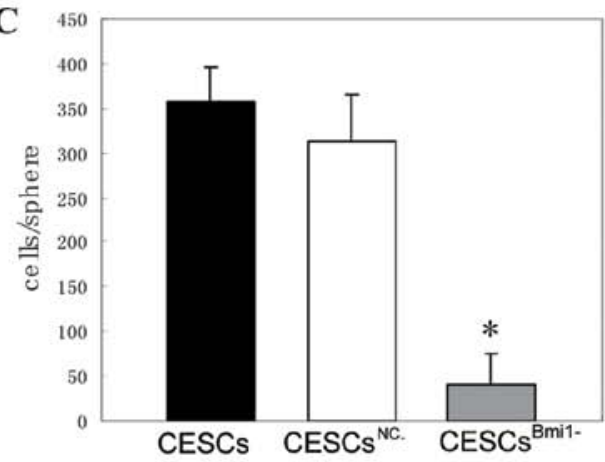

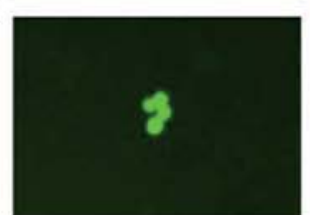

Day 4

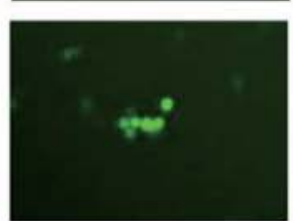

Day 6

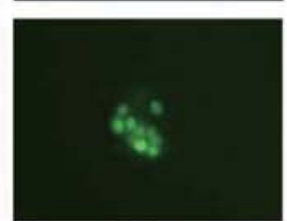

Day 10

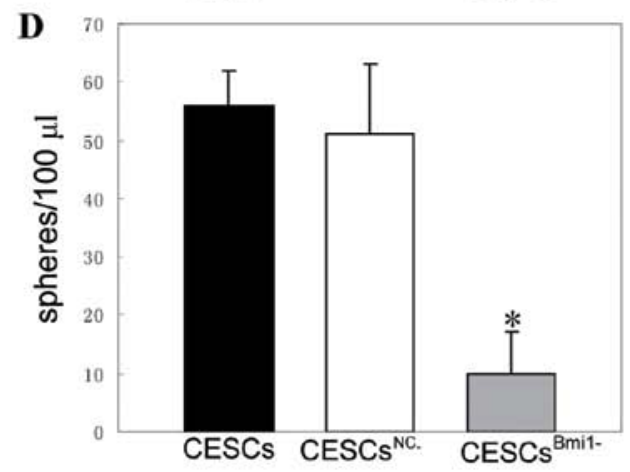

E

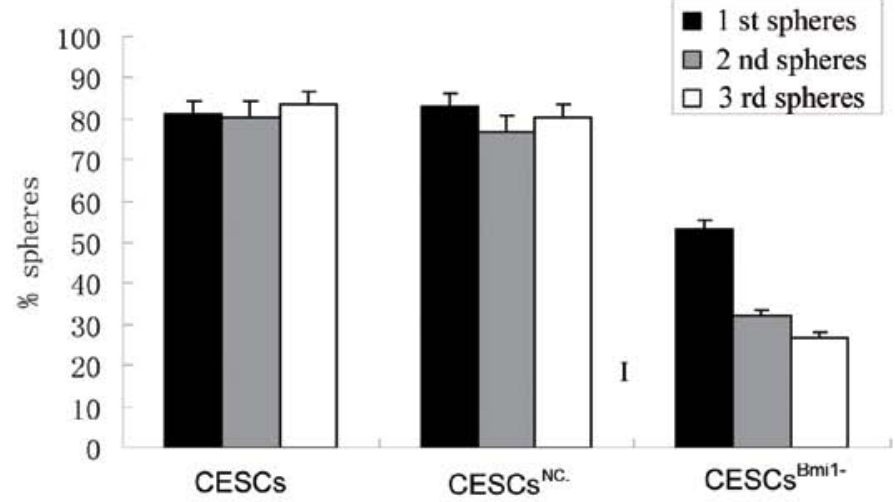

Figure 6. (A) Images of tumor spheres generated from clonal density cultures of CESCs, CESCs ${ }^{\text {NC- }}$ and CESCs ${ }^{\text {Bmil- }}$ collected 10 days after the start of suspension cultures. (B) Images of tumor spheres generated from single-cell cultures of CESCs, CESCs ${ }^{\mathrm{NC}-}$ and CESCs ${ }^{\mathrm{Bmil}-}$ taken on the indicated day of suspension culture using time-lapse microscopy. (C) Quantification of the number of cells per sphere counted after 10 days of culturing for CESCs, CESCs ${ }^{\mathrm{NC}-}$ and $\mathrm{CESCs}^{\mathrm{Bmil}}$. Data are presented as the mean \pm SD. ${ }^{*} \mathrm{P}<0.001$ compared with CESCs. (D) The number of tumor spheres counted for CESCs, CESCs ${ }^{\mathrm{NC}-}$ and $\mathrm{CESCs}^{\mathrm{Bmil}-}$ in 100- $\mu 1$ samples. Data are presented as the mean \pm SD for triplicate counts. " $\mathrm{P}<0.001$ compared with CESCs. (E) Sphere-forming efficiency was detected consecutively for three passages of CESCs, $\mathrm{CESCs}^{\mathrm{NC}-}$ and $\mathrm{CESCs}^{\mathrm{Bmil}-}$. Bar graph represents the sphere-forming efficiency calculated by counting the number of wells with new spheres and dividing this by the total number of wells seeded as a single cell for each group, represented as percentage $(n=7)$.

from surgery to chemotherapy to the use of recently developed EGFR-targeted drugs, recurrence of lung cancer remains high.
A growing body of evidence suggests that cancer stem-like cells (CSCs) are chemoresistant and may be responsible for 
Table II. Incidence of tumors of CESCs, CESCs ${ }^{\text {Bmil- }}$ and $\mathrm{CESCs}^{\mathrm{NC}-}$ cells serially transplanted on NOD/SCID mice.

\begin{tabular}{lcccc}
\hline Cell number & $10^{5}$ & $10^{4}$ & $10^{3}$ & $10^{2}$ \\
\hline CESCs & 6 & 6 & 5 & 3 \\
& $10^{5}$ & $10^{4}$ & $10^{3}$ & $10^{2}$ \\
CESCs $^{\text {NC- }}$ & 6 & 6 & 4 & 3 \\
& $10^{5}$ & $10^{4}$ & $10^{3}$ & $10^{2}$ \\
CESCs $^{\text {Bmil- }}$ & 4 & 1 & 0 & 0 \\
\hline
\end{tabular}

Cells $\left(0^{5}, 10^{4}, 10^{3}\right.$ and $\left.10^{2}\right)$ were subcutaneously inoculated into 6 mice for each group. Tumors were monitored every 3 days for up to 60 days.

the observed tumor recurrence following treatment with chemotherapy. Due to the difficulty in recognizing CSCs, little is known regarding the regulatory mechanisms responsible for their capacity to self-renew and initiate tumor formation; therefore, the role of CSCs in tumor recurrence remains unclear.

Previous study has reported that chemotherapy drugs selectively kill non-stem-like cells (non-CSCs) lacking ABCG2 or other drug pumping mechanisms, resulting in an enrichment of stem-like cells (21). In this study, A549 lung cancer cells were treated with cisplatin to select for stemlike cells. To further exclude serum-dependent non-CSCs that may have been retained among the CSCs, cisplatinsurviving cells were sequentially passaged in serum-free media to obtain third-generation tumor spheres. These cells were considered to have the properties of stem-like cells, including the expression of CD133 and ABCG2, enhanced sphere formation capacities, differentiation, as well as the ability to form tumors in immune-deficient mice. Based on in vitro sphere forming assays and the proportion of $\mathrm{CD} 133^{+}$ cells detected, it is estimated that $>85 \%$ of the T3 spheres obtained were stem-like cells. Additionally, low levels of epithelial differentiation markers (i.e., cytokeratins 8/18) confirmed the undifferentiated status of T3 spheres. Based on these results, T3 spheres were considered to represent cisplatin-enriched stem-like cells (CESCs) and were further characterized.

Stem cells are traditionally regarded as quiescent cells and only respond to a proliferative signal when tissue repair is needed (29). In this study, the majority of A549 cells were eradicated using cisplatin treatment, creating a phenomenon resembling tissue repair. We observed that CESCs were not quiescent and formed tumor nodules within 1 week, whereas parental A549 cells required 4 weeks. These data indicate that CESCs had a high potential to proliferate and expand. Investigating the mechanism regulating CESCs proliferation and self-renewal is important for understanding how cancer stem-like cells initiate the tumor mass. The Polycomb group protein Bmil has been implicated in the development and progression of several malignancies $(30,31)$. With regard to stem cell biology, Bmil is essential for the self-renewal of adult murine hematopoietic stem cells and neuronal stem cells
$(32,33)$. Recently, it has been reported that Bmil is critical for bronchioalveolar stem cell expansion and lung tumorigenesis in a mouse model (20). In this study, we initially observed the expression of Bmil in CESCs and also found that Bmil was transcriptionally and translationally upregulated in CESCs compared with parental A549 cells. This may be due to the regulation of Bmil by certain transcriptional factors under the pressure of cisplatin or to the cells' need to proliferate. This mechanism is not of direct relevance to our study and will not be discussed here.

Because we have confirmed that Bmil is highly expressed in CESCs, it is reasonable to study the function of Bmil by decreasing its level of expression. We therefore developed a Bmil-targeted shRNA and inserted this construct into the A549 cell genome using a lentivirus, establishing a stable Bmil low-expressing cell line, CESCs ${ }^{\text {Bmil- }}$. Bmil-targeted shRNA resulted in a decrease in the proliferative potential of CESCs as shown on the WST-1 assay that was unrelated to cell death. Additionally, flow cytometry demonstrated a G1

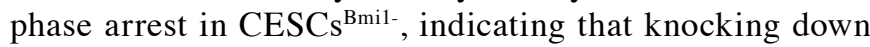
Bmil influenced the cell cycle and resulted in impaired cell proliferation. We also tested the function of Bmil in the regulation of CESCs self-renewal using the sphere-forming assay both from colonies and from single cells. CESCs ${ }^{\text {Bmil- }}$ formed fewer spheres compared to CESCs, and the size of $\mathrm{CESCs}^{\mathrm{Bmil}-}$ spheres was smaller due to a lower average cell count in CESCs ${ }^{\text {Bmil- }}$ spheres relative to CESCs. Selfrenewal of CESCs ${ }^{\mathrm{Bmil}-}$, CESCs and $\mathrm{CESCs}^{\mathrm{NC}-}$ at the single cell level was also studied. Knock down of Bmil resulted in a decreased ratio of sphere-forming cells, indicating the Bmil is required to maintain stem cell number by promoting self-renewal. Additionally, in vivo studies demonstrated that

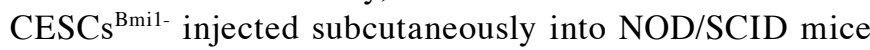
exhibited a lower tumorigenic potential. Based on these data, Bmil plays a crucial role in maintaining the self-renewing capacity of CESCs.

Drug-resistance of CSCs represents a significant obstacle in the treatment of cancers with chemotherapy. In lung cancer particularly, non-small cell lung cancer (NSCLC), chemotherapy often results in tumor recurrence within 1-2 years following treatment, as well as a restoration of pre-treatment tumor size. In this study, we used the lung cancer A549 cell line to study the role of stem-like cells in tumor recurrence following chemotherapy. We enriched CESCs using cisplatin treatment and found that Bmil is a critical gene regulating CESCs proliferation and self-renewal. Our data provide important insight into the mechanism of lung cancer recurrence following chemotherapy.

\section{Acknowledgements}

This project was supported by a grant from the National Natural Science Foundation of China (NSFC, no. 30772144). We thank Jin Li (Respiratory Disease Research Center, The Second Affiliated Hospital of Third Military Medical University, Chongqing, China) for her technical assistance in flow cytometry, and Lixia Guang (Central Laboratory, The Second Affiliated Hospital of Third Military Medical University, Chongqing, China) for providing laboratory instruments and analytic software. 


\section{References}

1. Shackleton M, Quintana E, Fearon ER and Morrison SJ: Heterogeneity in cancer: cancer stem cells versus clonal evolution. Cell 138: 822-829, 2009.

2. Vermeulen L, Todaro M, de Sousa Mello F, et al: Single-cell cloning of colon cancer stem cells reveals a multi-lineage differentiation capacity. Proc Natl Acad Sci USA 105: 13427-13432, 2008.

3. Dick JE: Stem cell concepts renew cancer research. Blood 112: 4793-4807, 2008.

4. Bonnet D and Dick JE: Human acute myeloid leukemia is organized as a hierarchy that originates from a primitive hematopoietic cell. Nat Med 3: 730-737, 1997.

5. Harrison H, Farnie G, Howell SJ, et al: Regulation of breast cancer stem cell activity by signaling through the Notch 4 receptor. Cancer Res 70: 709-718, 2010.

6. Visvader JE and Lindeman GJ: Cancer stem cells in solid tumours: accumulating evidence and unresolved questions. Nat Rev Cancer 8: 755-768, 2008.

7. Kim CF, Jackson EL, Woolfenden AE, et al: Identification of bronchioalveolar stem cells in normal lung and lung cancer. Cell 121: 823-835, 2005

8. Eramo A, Lotti F, Sette G, et al: Identification and expansion of the tumorigenic lung cancer stem cell population. Cell Death Differ 15: 504-514, 2008.

9. Seo DC, Sung JM, Cho HJ, et al: Gene expression profiling of cancer stem cell in human lung adenocarcinoma A549 cells. Mol Cancer 6: 75, 2007.

10. Ho MM, Ng AV, Lam S and Hung JY: Side population in human lung cancer cell lines and tumors is enriched with stem-like cancer cells. Cancer Res 67: 4827-4833, 2007.

11. Al-Hajj M, Wicha MS, Benito-Hernandez A, Morrison SJ and Clarke MF: Prospective identification of tumorigenic breast cancer cells. Proc Natl Acad Sci USA 100: 3983-3988, 2003.

12. Sullivan JP, Minna JD and Shay JW: Evidence for self-renewing lung cancer stem cells and their implications in tumor initiation, progression, and targeted therapy. Cancer Metastasis Rev 29: 61-72, 2010.

13. Maeda R, Yoshida J, Hishida T, et al: Late recurrence of non-small cell lung cancer more than 5 years after complete resection: incidence and clinical implications in patient followup. Chest 138: 145-150, 2010.

14. Dean M, Fojo T and Bates S: Tumour stem cells and drug resistance. Nat Rev Cancer 5: 275-284, 2005.

15. Dylla SJ, Beviglia L, Park IK, et al: Colorectal cancer stem cells are enriched in xenogeneic tumors following chemotherapy. PLoS One 3: e2428, 2008.

16. Eramo A, Ricci-Vitiani L, Zeuner A, et al: Chemotherapy resistance of glioblastoma stem cells. Cell Death Differ 13: 1238-1241, 2006.
17. Tamase A, Muraguchi $\mathrm{T}$, Naka $\mathrm{K}$, et al: Identification of tumor-initiating cells in a highly aggressive brain tumor using promoter activity of nucleostemin. Proc Natl Acad Sci USA 106: 17163-17168, 2009.

18. Malanchi I, Peinado H, Kassen D, et al: Cutaneous cancer stem cell maintenance is dependent on beta-catenin signalling. Nature 452: 650-653, 2008.

19. Korkaya $\mathrm{H}$, Paulson A, Iovino $\mathrm{F}$ and Wicha MS: HER2 regulates the mammary stem/progenitor cell population driving tumorigenesis and invasion. Oncogene 27: 6120-6130, 2008.

20. Dovey JS, Zacharek SJ, Kim CF and Lees JA: Bmi1 is critical for lung tumorigenesis and bronchioalveolar stem cell expansion. Proc Natl Acad Sci USA 105: 11857-11862, 2008.

21. Levina V, Marrangoni AM, DeMarco R, Gorelik E and Lokshin AE: Drug-selected human lung cancer stem cells: cytokine network, tumorigenic and metastatic properties. PLoS One 3: e3077, 2008.

22. Bea S, Tort F, Pinyol M, et al: BMI-1 gene amplification and overexpression in hematological malignancies occur mainly in mantle cell lymphomas. Cancer Res 61: 2409-2412, 2001.

23. Tsunoda S, Okumura T, Ito T, et al: ABCG2 expression is an independent unfavorable prognostic factor in esophageal squamous cell carcinoma. Oncology 71: 251-258, 2006.

24. Donnenberg VS and Donnenberg AD: Multiple drug resistance in cancer revisited: the cancer stem cell hypothesis. J Clin Pharmacol 45: 872-877, 2005.

25. Tredan O, Galmarini CM, Patel K and Tannock IF: Drug resistance and the solid tumor microenvironment. J Natl Cancer Inst 99: 1441-1454, 2007.

26. Eyler CE and Rich JN: Survival of the fittest: cancer stem cells in therapeutic resistance and angiogenesis. J Clin Oncol 26: 2839-2845, 2008.

27. Kanaji N, Bandoh S, Fujita J, Ishii T, Ishida T and Kubo A: Compensation of type I and type II cytokeratin pools in lung cancer. Lung Cancer 55: 295-302, 2007.

28. Li L and Neaves WB: Normal stem cells and cancer stem cells: the niche matters. Cancer Res 66: 4553-4557, 2006.

29. Beachy PA, Karhadkar SS and Berman DM: Tissue repair and stem cell renewal in carcinogenesis. Nature 432: 324-331, 2004.

30. Park IK, Morrison SJ and Clarke MF: Bmi1, stem cells, and senescence regulation. J Clin Invest 113: 175-179, 2004.

31. Zhang HW, Ding J, Jin JL, et al: Defects in mesenchymal stem cell self-renewal and cell fate determination lead to an osteopenic phenotype in Bmi-1 null mice. J Bone Miner Res 25: 640-652, 2010.

32. Shakhova O, Leung $\mathrm{C}$ and Marino S: Bmil in development and tumorigenesis of the central nervous system. J Mol Med 83: 596-600, 2005

33. van der Lugt NM, Domen J, Linders K, et al: Posterior transformation, neurological abnormalities, and severe hematopoietic defects in mice with a targeted deletion of the bmi-1 protooncogene. Genes Dev 8: 757-769, 1994. 